\title{
MiR-449a-5p regulates the proliferation of esophageal carcinoma cell by targeting B-cell lymphoma 2
}

\author{
Tao Jiang ${ }^{1}$, Ruixing Zhao ${ }^{2}$, Yanyan $\mathrm{Du}^{1}$, Zhihua Shi ${ }^{1}$, Hongchun Cheng ${ }^{3}$ \\ ${ }^{1}$ Department of Thoracic Surgery, Fourth Hospital of Hebei Medical University, Shijiazhuang, China; ${ }^{2}$ Department of Thoracic Surgery, The \\ Second People's Hospital of Liaocheng, Liaocheng, China; ${ }^{3}$ Department of Thoracic Surgery, The Sixth People's Hospital of Yancheng City, \\ Yancheng, China \\ Contributions: (I) Conception and design: T Jiang, R Zhao; (II) Administrative support: T Jiang; (III) Provision of study materials or patients: Y Du, T \\ Jiang; (IV) Collection and assembly of data: Y Du , T Jiang; (V) Data analysis and interpretation: Z Shi, T Jiang, H Cheng; (VI) Manuscript writing: \\ All authors; (VII) Final approval of manuscript: All authors. \\ Correspondence to: Prof. Hongchun Cheng. Department of Thoracic Surgery, The Sixth People's Hospital of Yancheng City, Yancheng 224000, China. \\ Email: 18361686333@163.com
}

Background: Esophageal cancer (EC) is a common malignancy that claims millions of lives globally each
year. Impairment of esophageal carcinoma cell proliferation could provide a therapeutic approach to treating
EC. MiR-449a-5p has been put forward as a crucial tumor suppressor in multiple cancers. In this study, we
aimed to determine the mechanism underlying the regulating effect of miR-449a-5p on EC cell proliferation.
Methods: The level of miR-449a-5p in esophageal squamous cell carcinoma (ESCC) tissues and adjacent
normal esophageal squamous tissues was detected using real-time polymerase chain reaction. The protein
level of B-cell lymphoma 2 (Bcl-2) was measured by western blot. MTT and colony formation assays were
carried out to assess Eca-109 cell proliferation.

Results: The level of miR-449a-5p in ESCC tissues was reduced in comparison with that in adjacent normal tissues. Down-regulation of miR-449a-5p promoted the proliferation of ESCC cells. Bcl-2 was established as a target gene of miR-449a-5p, and its silencing resulted in the reversal of the effects of miR$449 a-5 p$ inhibitor on the proliferation of Eca-109 cells.

Conclusion: Overexpression of miR-449a-5p inhibited the proliferation of Eca-109 cells via negative regulation of $\mathrm{Bcl}-2$.

Keywords: Esophageal squamous carcinoma tissues; miR-449a-5p; B-cell lymphoma 2 (Bcl-2)

Submitted Aug 21, 2020. Accepted for publication Nov 17, 2020.

doi: 10.21037/tcr-20-2869

View this article at: http://dx.doi.org/10.21037/tcr-20-2869

\section{Introduction}

Esophageal cancer (EC) is a common malignancy that is responsible for millions of deaths around the world every year. Approximately 456,000 new EC cases are diagnosed annually (1). The cure rate for EC is poor, and it ranks as the sixth deadliest malignancy (2). For non-metastatic and metastatic EC patients, the 5-year survival rates are $43 \%$ and $5 \%$, respectively $(1,3)$. EC comprises two subtypes: esophageal adenocarcinoma (EAC) and esophageal squamous cell carcinoma (ESCC) (4). In China, ESCC is the predominant subtype (5). Many risk factors for ESCC have been established, including alcohol consumption, smoking, and an unhealthy lifestyle (6). Consuming food or drink at a high temperature may also contribute to an increased risk of EC. For early-stage EC, surgical resection is the main therapeutic strategy (7), while for advanced EC, chemotherapy and radiotherapy are the main treatments. Due to the limitations of the current treatment options, 5 -year survival for EC patients is extremely low. Further breakthroughs are urgently needed in EC therapy. The proliferation and metastasis of EC cells are the most 
Table 1 The sequences of microRNA oligos

\begin{tabular}{ll}
\hline Sequences & MicroRNA oligos \\
\hline NC sense & 5'-UUCUCCGAACGUGUCACGU-3' \\
NC anti-sense & 5'-ACGUGACACGUUCGGAGAA-3' \\
449aM sense & 5'-UGGCAGUGUAUUGUUAGCUGGU-3' \\
449aM anti-sense & 5'-CAGCUAACAAUACACUGCCAUU-3' \\
NCI & 5'-CAGUACUUUUGUGUAGUACAA-3' \\
$449 a l$ & 5'-ACCAGCUAACAAUACACUGCCA-3' \\
\hline
\end{tabular}

important factors for the development of the disease. Therefore, the impairment of EC cell proliferation is a key therapeutic strategy for patients with EC. In this study, we explored the mechanism underlying the proliferation of EC cells.

MicroRNAs (miRNAs), which are small non-coding RNAs with conserved sequences, are expressed in all tissue types. MiRNAs can engage in the negative regulation of protein expression by complementarily binding to the 3'-untranslated region (3'-UTR) of their target genes (8). The involvement of MiRNAs in the pathogenesis of various cancers through their targeting of important oncogenes and tumor suppressor genes has been described previously (9). MiRNAs also participate in numerous biological cellular processes, such as differentiation, proliferation, migration, and apoptosis $(10,11)$. Dysregulation of miRNAs is related to the development of several tumors, including gastric cancer (12), lung cancer (13), and liver cancer (14). MiR-449a-5p has tumor-suppressive qualities and negatively regulates the expression of many oncogenes (15). In this study, we aimed to explore the mechanism underlying the regulating effect of miR-449a-5p on the proliferation of Eca-109 cells.

We present the following article in accordance with the MDAR reporting checklist (available at http://dx.doi. org/10.21037/tcr-20-2869).

\section{Methods}

\section{ESCC tissue specimens}

Forty pairs of tumor tissues and adjacent normal esophageal squamous tissues were obtained from ESCC patients who underwent esophagogastrostomy in The Fourth Hospital of Hebei Medical University from January 2015 to December 2019. The study participants had an average age of $61.6 \pm 8.0$ (range, $47-73$ ) years; 25 patients were male and 15 were female. None of the patients were administered chemotherapy or radiotherapy preoperatively. Clinicopathological features of the patients were collected for the analysis. The ESCC tissues and adjacent normal tissues were all stored in liquid nitrogen. The Ethical Review Committee of the Fourth Hospital of Hebei Medical University granted approval for this study. Each patient signed an informed consent form. The study was carried out in line with the Declaration of Helsinki (as revised in 2013).

\section{Eca-109 cell culture}

Human EC cell line Eca-109 was supplied by American Type Culture Collection (USA). Culture of Eca-109 cells in Roswell Park Memorial Institute-1640 (RPMI-1640) supplemented with $10 \%(\mathrm{v} / \mathrm{v})$ fetal bovine serum (FBS) (Gibco, Thermo), penicillin (80 unit/mL) and streptomycin $(100 \mu \mathrm{g} / \mathrm{mL})$ (Life Technologies, Inc.) was conducted, and the cell culture was maintained at $37^{\circ} \mathrm{C}$ with $5 \% \mathrm{CO}_{2}$.

\section{Transfection with miR-449a-5p mimic or miR-449a-5p inbibitor}

Negative control mimic (NC), miR-449a-5p mimic (449aM), negative control inhibitor (NCI), and miR449a-5p inhibitor (449aI) were obtained from Genepharm (China). HiPerfect Transfection Reagent (Qiagen) was used to transfect miRNA oligos into Eca-109 cells following the manufacturer's protocol. In short, the day prior to transfection, $1.0 \times 10^{5}$ cells were seeded in a 6 -well-plate. All miRNA oligos were diluted in $150 \mu \mathrm{L}$ double-distilled water $\left(\mathrm{ddH}_{2} \mathrm{O}\right)$ to $20 \mu \mathrm{m}$ solution. Then, $2 \mu \mathrm{L}$ miRNA oligos solution $(20 \mu \mathrm{m})$ and $3 \mu \mathrm{L}$ Hiperfect transfection reagent were added to $100 \mu \mathrm{L}$ RPMI-1640. After incubation at room temperature for $10 \mathrm{~min}$, the mixture was added to each well. The cells were cultured further at $37^{\circ} \mathrm{C}$ in an atmosphere of $5 \% \mathrm{CO}_{2}$ for $48 \mathrm{~h}$. Sequences of the miRNA oligos are described in Table 1.

\section{Reverse transcription and real-time polymerase chain reaction}

After $48 \mathrm{~h}$ of microRNA oligo transfection, cells were harvested and total RNA extraction was performed with TRIzol Reagent (Invitrogen) according to the protocol supplied by the manufacturer. RNA samples extracted from 
Table 2 The sequences of microRNA-specific strand-loop RT-primers

\begin{tabular}{ll}
\hline Primer & Sequences \\
\hline MiR-449a-5p RT & 5'-GTCGTATCCAGTGCAGGGTCCGAGGTATTCGCACTGGATACGACGCTTTG-3' \\
U6 RT & 5'-GTCGTATCCAGTGCAGGGTCCGAGGTATTCGCACTGGATACGACAAAAATATG-3' \\
\hline
\end{tabular}

Table 3 The sequences of real-time PCR primers

\begin{tabular}{ll}
\hline Primer & Sequences \\
\hline MiR-449a-5p forward & 5'-ATAGTGGCAGTGTATTGTTAG-3' \\
U6 forward & 5'-GCGCGTCGTGAAGCGTTC-3' \\
Universal reverse primer & 5'-GTGCAGGGTCCGAGGT-3' \\
\hline
\end{tabular}

Table 4 The sequences of PCR primers

\begin{tabular}{ll}
\hline Primer & Sequences \\
\hline Bcl-2-F-EcoRI & 5'-TCGAATTCCACAGACAGACACACACACA-3' \\
Bcl-2-R-Xbal & 5'-GCTCTAGAAGGCACAGAACATCCAGGTG-3' \\
\hline
\end{tabular}

cells and tissues were diluted with diethyl pyrocarbonatetreated water (DEPC $\mathrm{H}_{2} \mathrm{O}$ ) into a $1 \mu \mathrm{g} / \mu \mathrm{L}$ RNA solution. First, $1 \mu \mathrm{L}$ RNA was mixed with $1 \mu \mathrm{L}$ microRNA-specific strand-loop reverse transcription (RT)-primer $(500 \mathrm{~nm})$, $2 \mu \mathrm{L}$ dNTP $(10 \mathrm{mM})$, and $6 \mu \mathrm{L}$ DEPC $\mathrm{H}_{2} \mathrm{O}$. Next, the mixture was heated at $70{ }^{\circ} \mathrm{C}$ for $10 \mathrm{~min}$, and then cooled to $4{ }^{\circ} \mathrm{C}$. Following that, $0.5 \mu \mathrm{L}$ MMLV Reverse Transcriptase $(200 \mathrm{U} / \mu \mathrm{L}), 2 \mu \mathrm{L} 10 \times$ Transcriptase Buffer, $0.5 \mu \mathrm{L}$ Recombinant RNase inhibitor $(40 \mathrm{U} / \mu \mathrm{L})$, and $7 \mu \mathrm{L}$ DEPC $\mathrm{H}_{2} \mathrm{O}$ were added into the polymerase chain reaction (PCR) tube; the mixture was heated at $42{ }^{\circ} \mathrm{C}$ for $60 \mathrm{~min}, 95^{\circ} \mathrm{C}$ for $5 \mathrm{~min}$, and cooled to $4^{\circ} \mathrm{C}$. The primer sequences used for RT are described in Table 2.

The expression level of miR-449a-5p was measured by real-time quantitative PCR. Briefly, $10 \mu \mathrm{L}$ cDNA was mixed with $90 \mu \mathrm{L} \mathrm{ddH}_{2} \mathrm{O}$. SYBR Green I kit (TaKaRa) was used to carry out real-time PCR in accordance with the manufacturer's instructions, with $1 \mu \mathrm{L}$ diluted cDNA used as template. Then, $1 \mu \mathrm{L}$ cDNA, $10 \mu \mathrm{L}$ SYBR Green mix,

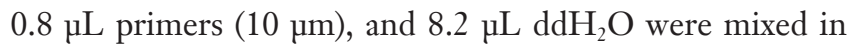
a PCR tube. The following reaction conditions were used: $95^{\circ} \mathrm{C}$ for $30 \mathrm{~s}$, followed by 40 cycles for $95^{\circ} \mathrm{C}$ for $5 \mathrm{~s}$, $60{ }^{\circ} \mathrm{C}$ for $20 \mathrm{~s}$. U6 small nucleolar RNA served as the housekeeping gene for normalization. The $2^{-\Delta \Delta \mathrm{Ct}}$ method was employed to quantify the relative expression level of miR-449a-5p/U6. Each reaction was performed in triplicate. Table 3 lists the primer sequences used.

\section{Luciferase reporter assay}

MiRNAs negatively regulate their target genes. TargetScan (http://www.targetscan.org/), miRanda (http://www. targetscan.org/), and PicTar (http://pictar.mdc-berlin. de/) were employed for the prediction of miR-449a-5p's target gene. B-cell lymphoma 2 (Bcl-2) was identified as a predicted target gene of miR-449a-5p. A predicted binding site of miR-449a-5p was located on the 3'-UTR of Bcl2 messenger RNA (mRNA). DNA fragments of the 3'UTR of Bcl-2 mRNA were cloned by PCR. The primer sequences used for PCR are described in Table 4 (restriction sites are underlined).

The extraction of genomic DNA from Eca-109 cells was performed with a genomic DNA extraction kit, in line with the manufacturer's protocol. Genomic DNA $(1 \mu \mathrm{g})$ was used as the PCR template. We created a mixture with $1 \mu \mathrm{g}$ sample of genomic DNA $(1 \mu \mathrm{g} / \mu \mathrm{L}), 0.8 \mu \mathrm{L}$ primers

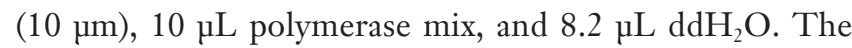
PCR conditions were as follows: $95^{\circ} \mathrm{C}$ for $10 \mathrm{~min}$, followed by 40 cycles for $95{ }^{\circ} \mathrm{C}$ for $15 \mathrm{~s}, 55^{\circ} \mathrm{C}$ for $45 \mathrm{~s}, 72{ }^{\circ} \mathrm{C}$ for $1 \mathrm{~min}$, then $72{ }^{\circ} \mathrm{C}$ for $2 \mathrm{~min}$, and cooled to $4^{\circ} \mathrm{C}$. The PCR product was purified using a TaKaRa MiniBEST Agarose Gel Extraction Kit, and then endonuclease EcoRI and XbaI were used for digestion of the purified PCR. Finally, the DNA fragment was inserted into the pmiRGLO vector (Promega) with T4 ligase (Promega) to construct the recombinant luciferase vector (pmiRGLO-3'-UTR).

For the luciferase assay, Eca-109 cells underwent transfection with the recombinant luciferase vector, control vector, NC, miR-449a-5p mimic, NCI and miR449a-5p inhibitor using Effectene Transfection Reagent (Qiagen) following the manufacturer's instructions. One day before transfection, 5,000 Eca-109 cells were seeded in a 96-well plate and subsequently subjected to culture in $100 \mu \mathrm{L}$ RPMI-1640 supplemented with $10 \%(\mathrm{v} / \mathrm{v})$ FBS (Gibco), penicillin (80 unit/mL), and streptomycin $(100 \mu \mathrm{g} / \mathrm{mL})$. Next, $3.75 \mu \mathrm{L}$ miRNA mimic or inhibitor $(20 \mu \mathrm{m}), 2 \mathrm{~g}$ vector or recombinant vector, $116.25 \mu \mathrm{L}$ EC 
buffer, and $8 \mu \mathrm{L}$ enhancer buffer were added to $100 \mu \mathrm{L}$ medium. After mixing, the solution was incubated for $10 \mathrm{~min}$ at room temperature. Luciferase activity was detected with a dual-luciferase reporter assay system (Promega), with normalization to Renilla luciferase activity to control the transfection efficiency. All tests were performed in triplicate.

\section{MTT assay}

Cell proliferation was measured by MTT assay. Briefly, Eca-109 cells $\left(1 \times 10^{4}\right)$ were seeded in a 96-well plate and subjected to culture for 24,48 , or $72 \mathrm{~h}$. Then, the addition of $20 \mu \mathrm{L}$ MTT $(10 \mathrm{mg} / \mathrm{mL})$ was made to each well, and the cells were incubated at $37{ }^{\circ} \mathrm{C}$ with $5 \% \mathrm{CO}_{2}$ for $4 \mathrm{~h}$. After the removal of the supernatant, $150 \mu \mathrm{L}$ dimethyl sulfoxide (DMSO) was added to the cells, which were then incubated at room temperature for 15-20 $\mathrm{min}$ to dissolve the purple formazan crystals. An enzyme-linked immunosorbent assay (ELISA) instrument was used to measure absorbance at $450 \mathrm{~nm}$. Each test was carried out six times.

\section{Colony formation assay}

One day after transfection with microRNA oligos, a 6-well plate was seeded with Eca-109 cells (300 cells per well) and maintained for 14 days at $37^{\circ} \mathrm{C}$ in an atmosphere containing $5 \% \mathrm{CO}_{2}$. The medium containing miRNA mimics or inhibitors transfection mixture was refreshed once a week. After washing three times with phosphate-buffered saline (PBS), the cells were fixed with $4 \%$ paraformaldehyde (PFA) at room temperature for $20 \mathrm{~min}$. Next, the cells were again washed three times with PBS, and dyed with $2.5 \%$ crystal violet staining solution (diluted in methanol) at room temperature for $30 \mathrm{~min}$. Then, after five more washes with PBS, the cells were dried at room temperature. The number of colonies in each well (containing $>50$ cells) was calculated with the bare eye. The relative colony number was determined as the ratio of the number of colonies formed by cells transfected with microRNA mimic or inhibitor to the number of colonies formed by cells transfected with negative control mimic or inhibitor. All tests were repeated three times.

\section{Western blot}

After 48 h of transfection with microRNA oligos, Eca-109 cells were harvested. Total protein was extracted using RIPA with protease inhibitor cocktail and phosphatase inhibitor cocktail. In line with the accompanying protocol, a BCA kit was used to determine the protein concentration of the samples. Samples of protein $(15 \mu \mathrm{L})$ extracted from the Eca109 cells were subjected to $10 \%$ sodium dodecyl sulfatepolyacrylamide gel electrophoresis (SDS-PAGE) separation followed by transfer to a polyvinylidene difluoride (PVDF) membrane (Millipore). Then, membrane blocking was carried out at room temperature for $2 \mathrm{~h}$ using $5 \%$ nonfat milk (diluted in tris-buffered saline with $0.1 \%$ Tween-20, TBST). The membrane was incubated with primary antibodies for Bcl-2, Bcl-2-associated X protein (BAX), and glyceraldehyde 3-phosphate dehydrogenase (GAPDH; 1:1,000 diluted in TBST). Then, the membrane was washed 5 times with TBST (10 min/time) and incubated with horseradish peroxidase (HRP)-labeled secondary antirabbit IgG (1:1,000 diluted in TBST) at room temperature for $2 \mathrm{~h}$. After washing the membrane 5 times $(10 \mathrm{~min} /$ time $)$ with TBST, we detected the protein bands using an enhanced chemiluminescence (ECL) kit in accordance with the protocol supplied with the kit. The relative protein expressions were determined with GAPDH used for normalization. All tests were repeated three times.

\section{Statistical analysis}

The SPSS 13.0 statistical software package was used to perform the data analyses in this study. All data were expressed as mean \pm standard error of the mean (SEM). Differences between two groups were analyzed using the non-parametric Mann-Whitney U test. Statistically significant differences between four groups were determined through one-way analysis of variance (ANOVA). $\mathrm{P}<0.05$ represented a statistically significant difference.

\section{Results}

\section{The relative levels of miR-449a-5p are decreased in ESCC tissues}

MiR-449a-5p expression was determined in 40 pairs of ESCC tissues and adjacent normal esophageal squamous tissues using real-time PCR. Figure $1 A$ shows that the relative level of miR-449-5p in ESCC tissues was decreased in comparison to that in the adjacent normal tissues $(\mathrm{P}<0.01)$. Moreover, the level of miR-449a-5p in Eca-109 cells was lower than that in normal esophageal mucosal epithelial He-1A cells (Figure 1B). Further, we investigated 

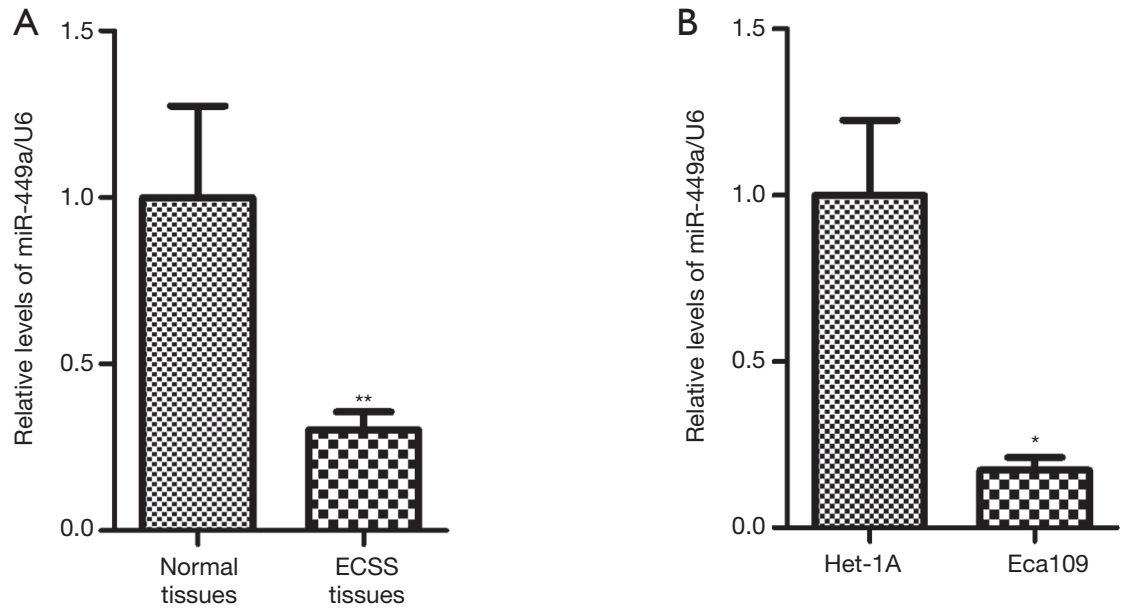

Figure 1 The level of miR-449a-5p was decreased in esophageal squamous carcinoma tissues. The relative expression of miR-449a-5p was analyzed in 40 pairs of ESCC tissues and adjacent normal tissues using real-time polymerase chain reaction (A). The relative expression of miR-449a-5p was determined in both normal esophageal mucosal epithelial Het-1A cells and esophageal squamous carcinoma Eca-109 cells (B). ${ }^{*} \mathrm{P}<0.05 ;{ }^{*} \mathrm{P}<0.01 ;$ vs. NT group or Het $-1 \mathrm{~A} ; \mathrm{n}=40$ or 4 .

the correlation of miR-449a-5p expression with the clinical characteristics of ESCC patients. As shown in Table 1, miR$449 a-5 p$ expression was correlated with tumor size and tumor node metastasis (TNM) stage (Table 5). Together, these findings suggested that miR-449a-5p might participate in the development of ESCC.

\section{MiR-449a-5p regulates the proliferation of ESCC cells}

In this study, the level of miR-449a-5p was found to be correlated with tumor size in ESCC tissues, indicating that miR-449a-5p could be a regulator of ESCC cell proliferation. Therefore, we explored whether decreased miR-449a-5p expression could promote Eca-109 cell proliferation. MiR-449a-5p inhibitor and miR-449a-5p mimic were synthesized and transfected into Eca-109 cells for $48 \mathrm{~h}$ to down-regulate and up-regulate the expression of miR-449a-5p, respectively. After transfection with miR449a-5p inhibitor, miR-449a-5p expression was decreased (Figure $2 A$ ), whereas miR-449a-5p mimic dramatically enhanced miR-449a-5p expression 40-fold (Figure 2B). Moreover, the results of colony formation assay showed that inhibition of miR-449a-5p stimulated colony formation of Eca-109 cells (Figure 2C), while upregulation of miR$449 a-5 p$ repressed the colony formation of Eca-109 cells (Figure 2D). The MTT assay revealed that miR-449a-5p inhibition significantly promoted the proliferation of Eca109 cells (Figure 2E), while up-regulation of miR-449a-5p inhibited Eca-109 cell proliferation (Figure 2F). Our data therefore indicated that miR-449 was able to regulate the proliferation of Eca-109 cells.

\section{$B c l-2$ is a target gene of miR-449a-5p}

MiRNAs function biologically via direct binding to the 3'-UTR of their target genes. Using the bioinformatics databases Miranda, TargetScan, and PicTar, we next predicted miR-449a-5p's target genes. A binding site of miR-449a-5p was predicted in the 3'-UTR of Bcl-2 at 188-210 nt (Figure 3A). Consequently, a DNA fragment containing the 3'-UTR of Bcl-2 within 188-210 nt was amplified and inserted into luciferase reporter vector pmiRLGO to construct the recombinant vector. Luciferase assay was used to determine whether miR-449a-5p could directly bind at the Bcl-2 3'-UTR. As shown in Figure 3B, transfection with miR-449a-5p mimic significantly decreased luciferase activity of Eca-109 cells, whereas cells transfected with miR-449a-5p inhibitor showed increased luciferase activity. Next, we determined whether miR$449 a-5 p$ could regulate the protein expression of Bcl-2. Transfection with miR-449a-5p mimic significantly reduced the protein expression of Bcl-2 in Eca-109 cells and induced the protein expression of Bax (Figure 3C). In contrast, transfection with miR-449a-5p inhibitor increased the protein expression of Bcl-2 in Eca-109 cells and decreased the protein expression of Bax (Figure 3D). Furthermore, we 
Table 5 The clinical feature of esophageal squamous carcinoma patients

\begin{tabular}{|c|c|c|c|c|c|}
\hline Clinical features & $\mathrm{n}$ & \multicolumn{4}{|c|}{ MiR-449a-5p } \\
\hline Age & & & & 0.90 & 0.34 \\
\hline$\leq 65$ years & 19 & 11 & 8 & & \\
\hline$>65$ years & 21 & 9 & 12 & & \\
\hline Male & 25 & 12 & 13 & & \\
\hline Female & 15 & 8 & 7 & & \\
\hline Smoker & & & & 1.62 & 0.20 \\
\hline Yes & 22 & 9 & 13 & & \\
\hline I-II & 18 & 13 & 5 & & \\
\hline III-IV & 22 & 7 & 15 & & \\
\hline Differentiation & & & & 0.42 & 0.52 \\
\hline Well/moderate & 24 & 13 & 11 & & \\
\hline Poor & 16 & 7 & 9 & & \\
\hline Length & & & & 6.64 & 0.01 \\
\hline$<5 \mathrm{~cm}$ & 22 & 15 & 7 & & \\
\hline$\geq 5 \mathrm{~cm}$ & 18 & 5 & 13 & & \\
\hline
\end{tabular}

quantified the protein level of Bcl-2 in ESCC tissues and adjacent normal tissues. The protein expression levels of Bcl-2 and Bax in ESCC tissues were found to be increased and decreased, respectively, compared with those in the adjacent normal tissues (Figure $4 A$ ). Moreover, a negative correlation was discovered between the relative protein level of Bcl-2 and the relative expression level of miR-449a-5p in ESCC tissues $(\mathrm{P}<0.01)$ (Figure $4 B)$. Taken together, the above results suggest that miR-449a-5p negatively regulated Bcl-2 expression by binding to its 3'UTR.

\section{MiR-449a-5p regulates Eca-109 cell proliferation via targeting Bcl-2}

To determine the role of Bcl-2 in Eca-109 cell proliferation induced by miR-449a-5p inhibitor, Eca-109 cells were cotransfected with siRNA targeting Bcl-2 mRNA and miR449a-5p inhibitor. The protein level of Bcl-2 in Eca-109 cells transfected with siRNA targeting Bcl2 was decreased by approximately half compared with those transfected with the negative siRNA control (Figure $5 A$ ). Down-regulation of Bcl-2 rescued the effects of miR-449a-5p inhibitor on Eca-109 cell proliferation (Figure 5B,C). These findings demonstrate that miR-449a-5p targeted Bcl-2 to regulate Eca-109 cell proliferation.

\section{Discussion}

EC is the eighth most common cancer worldwide and has a high rate of mortality (1). Due to a majority of patients with EC being diagnosed with advanced disease, this malignancy has a dire 5-year survival rate. The inhibition of EC cell proliferation can improve the effect of treatment for EC. MiR-449a-5p has been confirmed as an important tumor suppressor in various cancers, including breast cancer (15), liver cancer (16), and prostate cancer (17). In our previous study, we determined that miR-449a-5p could directly regulate cyclin D1 protein expression as well as 
A

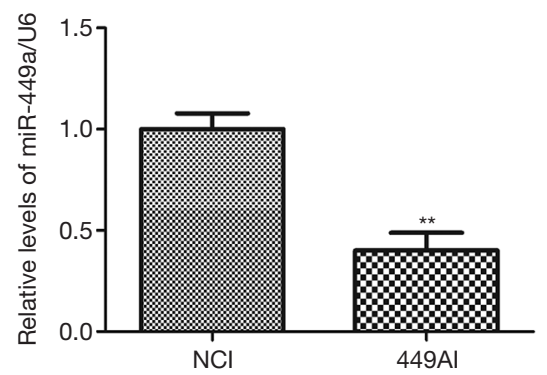

C
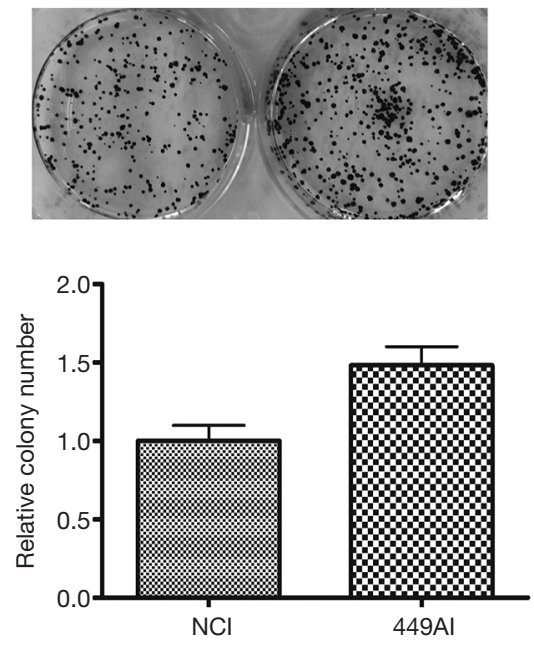

E

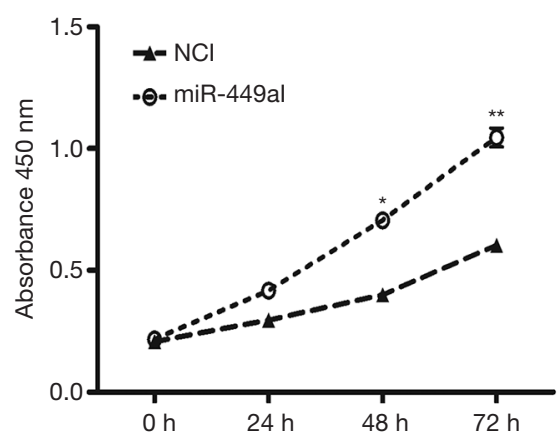

B

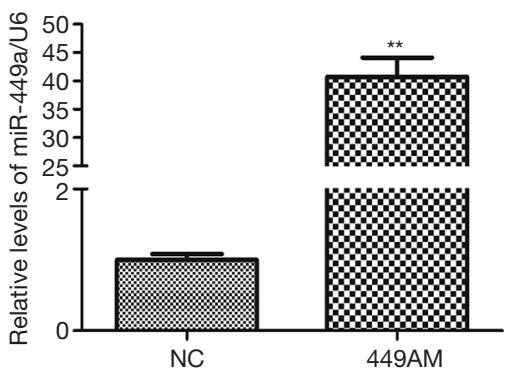

D
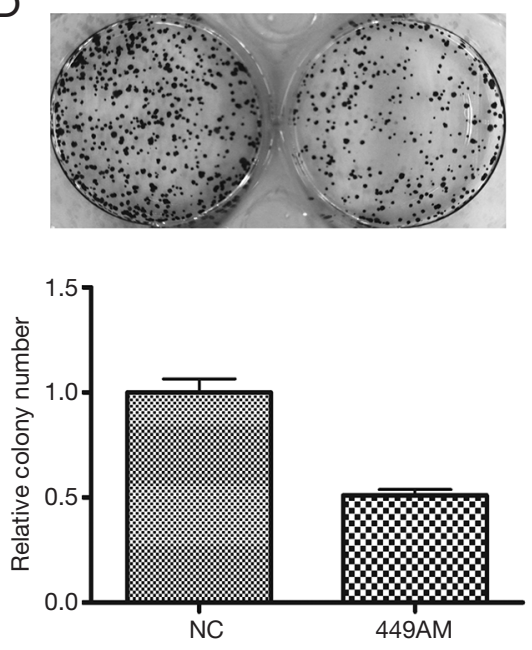

F

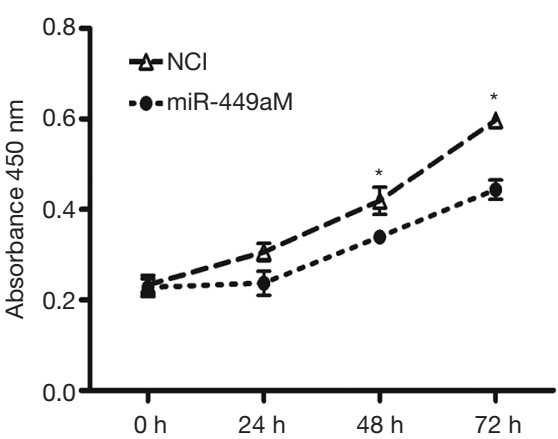

Figure 2 MiR-449a-5p regulated the proliferation of Eca-109 cells. The expression level of miR-449a-5p was measured in Eca-109 cells transfected with miR-449a-5p inhibitor (A) or miR-449a-5p mimic (B). Colony formation assay was used to determine the proliferation ability of Eca-109 cells transfected with miR-449a-5p inhibitor (C) or miR-449a-5p mimic (D). MTT assay was conducted to analyze the growth of Eca-109 cells transfected with miR-449a-5p inhibitor $(\mathrm{E})$ or miR-449a-5p mimic $(\mathrm{F}) .{ }^{*} \mathrm{P}<0.05 ;{ }^{* *} \mathrm{P}<0.01$ vs. control group; $\mathrm{n}=4$. 
A

3' uggucgavoguUaUgugacGgu 5' hsa-miR-449a |:| || :| || |||| 188:5' ucgaaucAGCUAUUUACUGCCa 3' BCL2

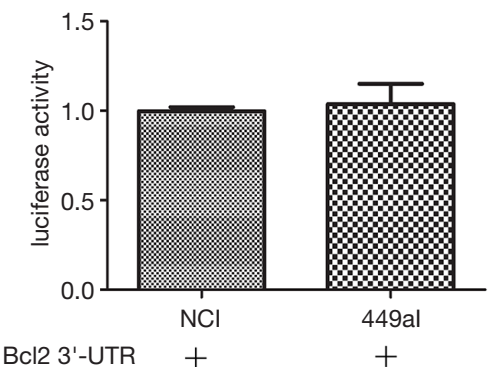

C
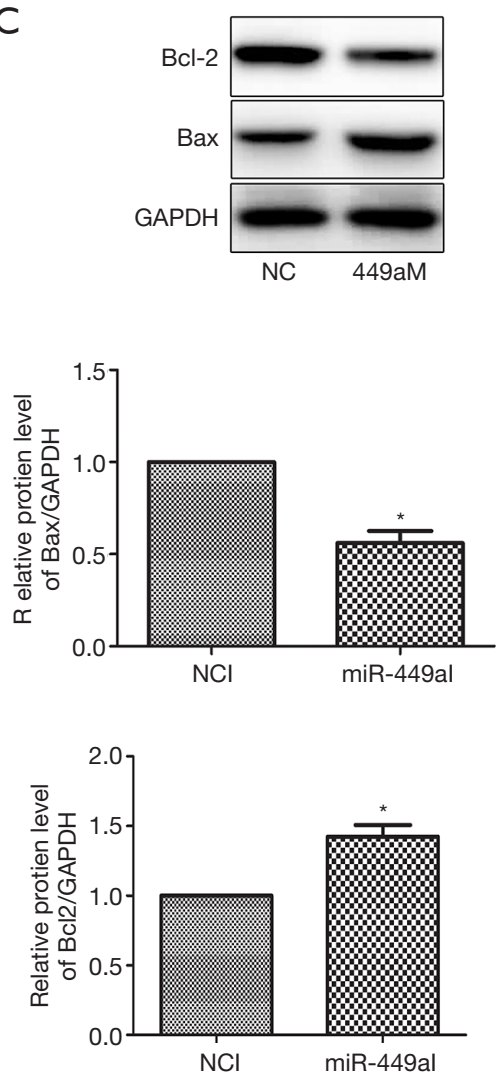

B
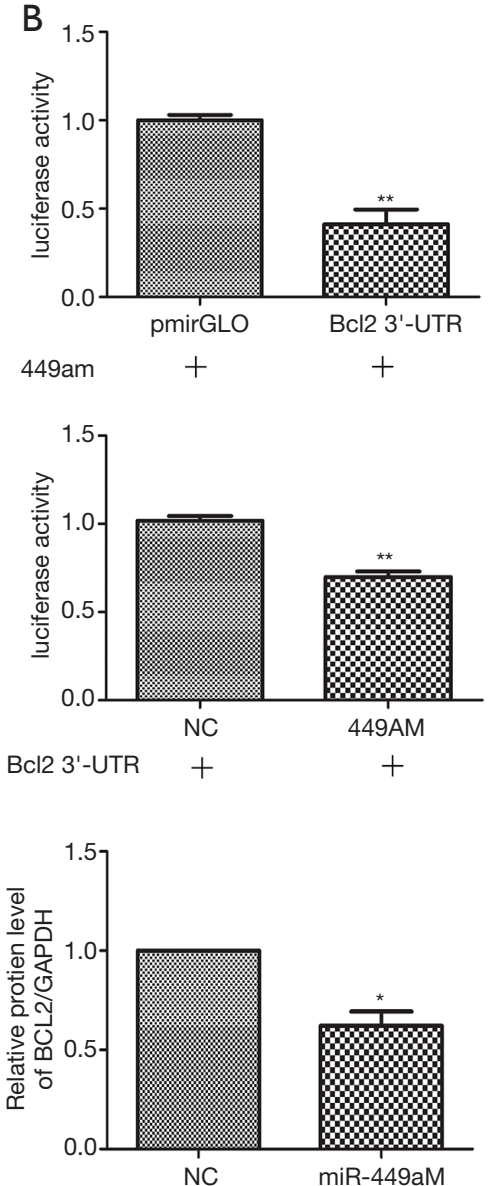

$\mathrm{D}$
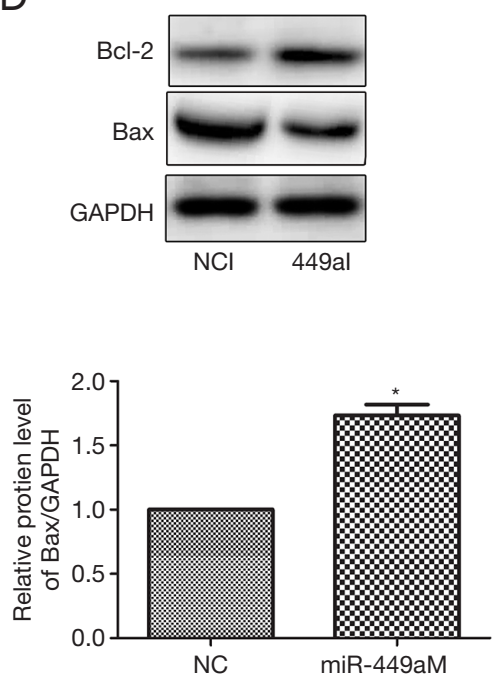

Figure 3 B-cell lymphoma 2 (Bcl-2) is a target gene of miR-449a-5p. Bioinformatics databases were used to predict the target gene of miR449a-5p. The three prime untranslated region of Bcl-2 at 188-210 nt was predicted as a binding site of miR-449a-5p (A). MiR-449a-5p inhibited the luciferase activity of Eca-109 cells transfected with recombinant vector Bcl-2 3'-UTR. (B). The protein levels of Bcl-2 and Bcl-2-associated X protein (Bax) were determined in Eca-109 cells transfected with miR-449a-5p mimic (C) or miR-449a-5p inhibitor (D). ${ }^{*} \mathrm{P}<0.05 ;{ }^{* *} \mathrm{P}<0.01$ vs. control group; $\mathrm{n}=4$. 
A
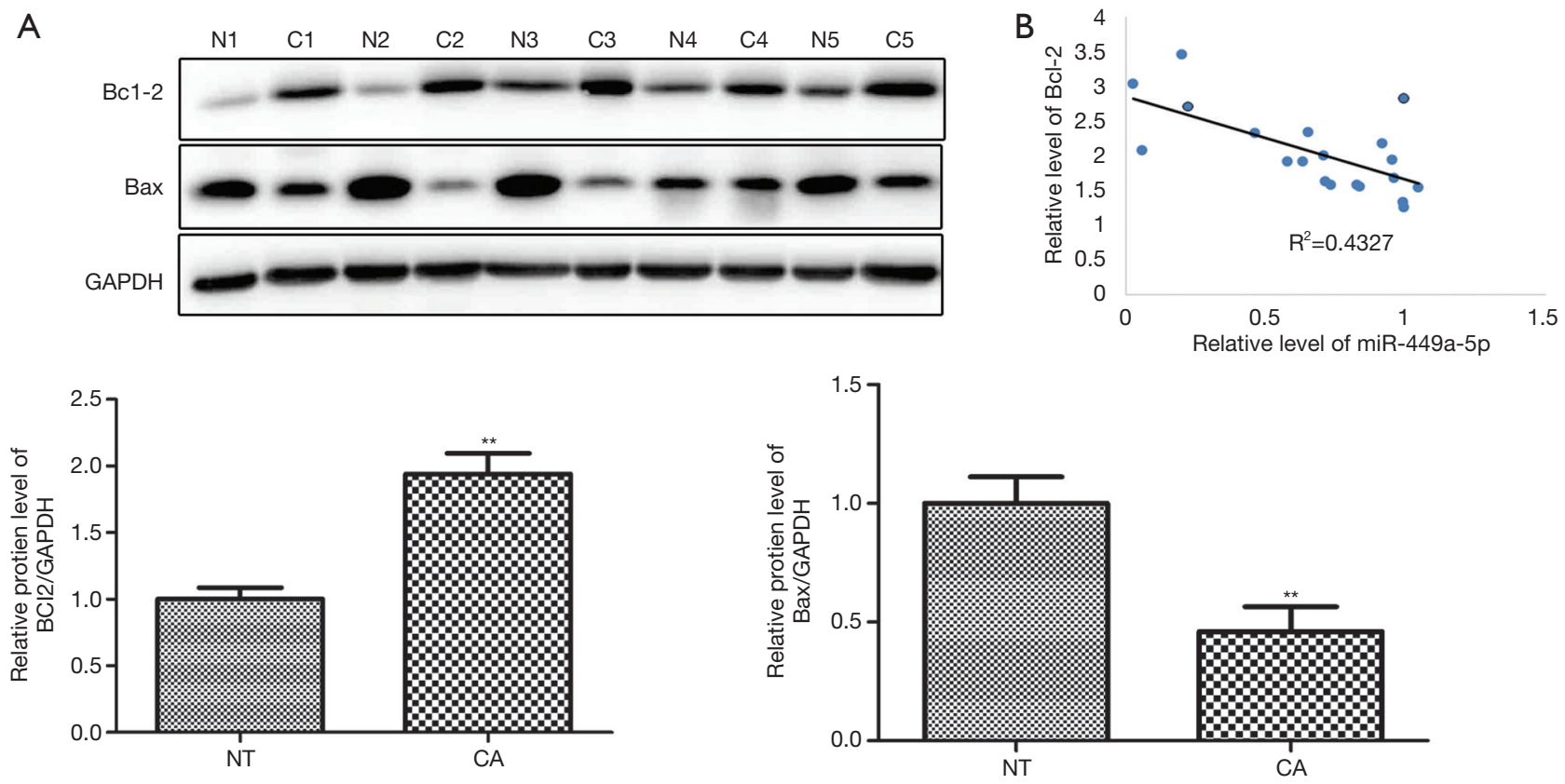

Figure 4 The protein level of B-cell lymphoma 2 (Bcl-2) was increased in esophageal squamous carcinoma tissues. The protein levels of $\mathrm{Bcl}-2$ and Bcl-2-associated X protein (Bax) were detected in adjacent normal esophageal squamous tissues (NT) and esophageal squamous carcinoma tissues (A). The relative protein level of Bcl-2 had a negative correlation with the relative level of miR-449a-5p in esophageal squamous carcinoma tissues (B). ${ }^{*} \mathrm{P}<0.01$ vs. control group; $\mathrm{n}=20$.

the proliferation of EC cells (18). In the current study, we discovered that Bcl-2 was another target gene of miR-449a$5 p$ and that miR-449a-5p was able to regulate Eca-109 cell proliferation through its targeting of Bcl-2.

According to their structural and functional characteristics, Bcl-2 family members are grouped across three subfamilies into pro-apoptotic and anti-apoptotic proteins (19). The anti-apoptotic subfamily comprises six proteins, Bcl-2, B-cell lymphoma X (Bcl-XL), B-cell lymphoma W (Bcl-W), Bcl-2-related protein A1 (Bfl-1/ A1), myeloid cell leukemia 1 (MCL-1), and BCL-B/Boo, which each contain four Bcl-2 homology $(\mathrm{BH})$ domains (BH1, BH2, BH3, and BH4). The pro-apoptotic members make up two subfamilies: one subfamily includes the multi-domain pro-apoptotic effectors Bcl-2 antagonist/ killer 1 (BAK) and Bcl-2 associated X (BAX), and has a short $\mathrm{BH} 2$ domain; the other subfamily includes Bcl2 associated agonist of (BAD), $\mathrm{BH} 3$-interacting doman death agonist (BID), Bcl-2-interacting killer (BIK), Bcl-2interacting mediator of cell death (BIM), Bcl-2-modifying factor (BMF), Histamine-releasing factor (HRF), p53upregulated mediator of apoptosis (PUMA), and NOXA. $\mathrm{Bcl}-2$ was the first gene verified to be a promoter of cell survival and to increase cell proliferation (20). It is a central regulator of apoptosis that is stimulated by environmental factors and as a response to several stress signals (21). Resistance to apoptosis is attributed with the development of cancer, cell colony formation, tumor growth, and failure of cancer treatment (22). The Bcl2 gene is on chromosome $18 \mathrm{q} 21.33$, which codes for a $26 \mathrm{kDa}$ protein located on the mitochondrial outer membrane, endoplasmic reticulum (ER) membrane, and nuclear envelope. Bcl-2 shares a similar structure with BclXL. Bcl-XL has the ability to co-sequester BAX and BAK, while Bcl-2 can only constrain BAX (23). Bcl-2 reportedly participates in many cancers, including hepatocellular carcinoma (24), prostate cancer (25), gastric cancer (26), and lung cancer (27). The present study showed Bcl2 protein expression to be increased in ESCC tissues and that silencing of Bcl-2 impaired the proliferation of Eca-109 cells. Moreover, Bcl-2 was established as a direct target of miR-449a-5p. The effect of miR-449a-5p inhibitor on Eca-109 cell proliferation could be reversed through inhibiting Bcl-2. In summary, the present study presents miR-449a-5p and Bcl-2 as effective biomarkers and potential therapeutic targets for ESCC. 

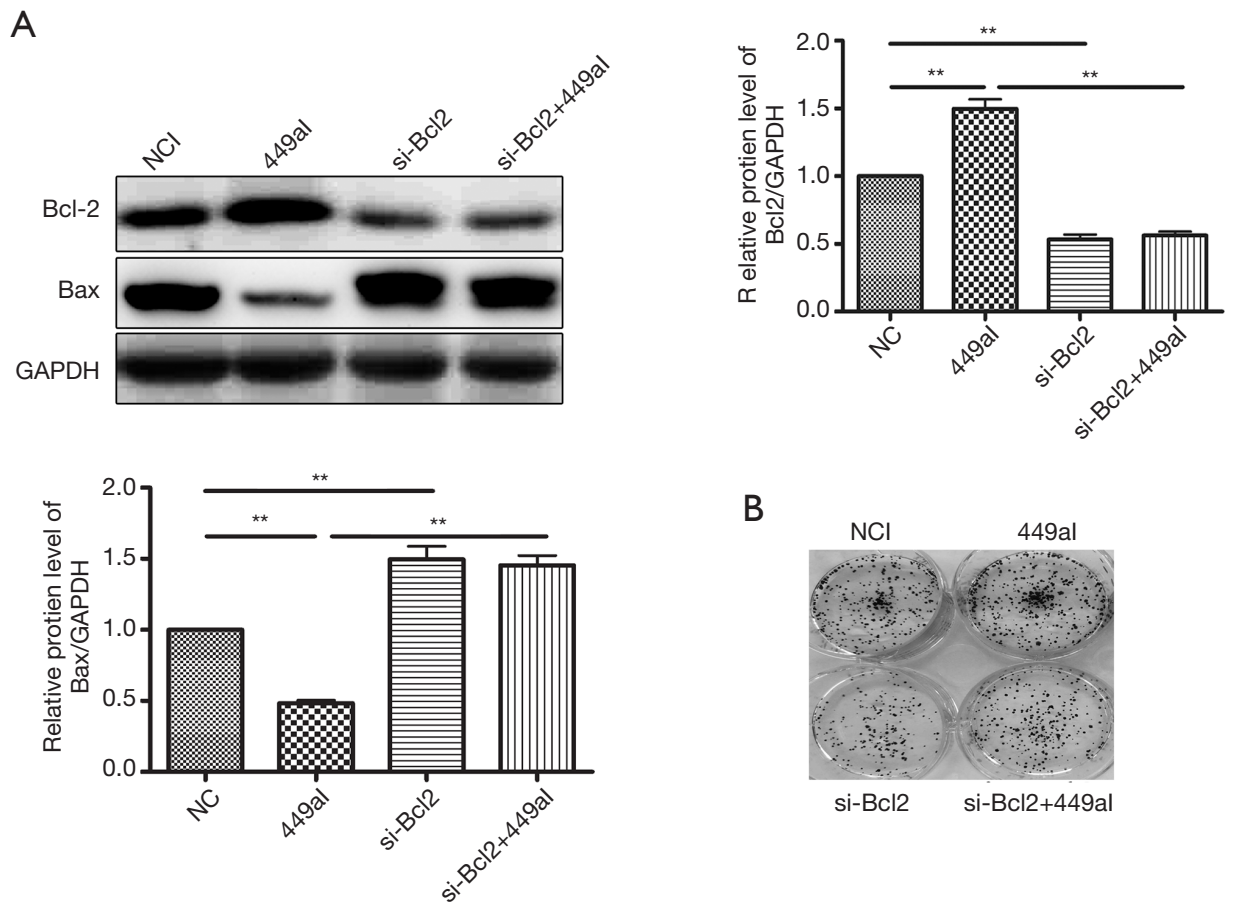

B
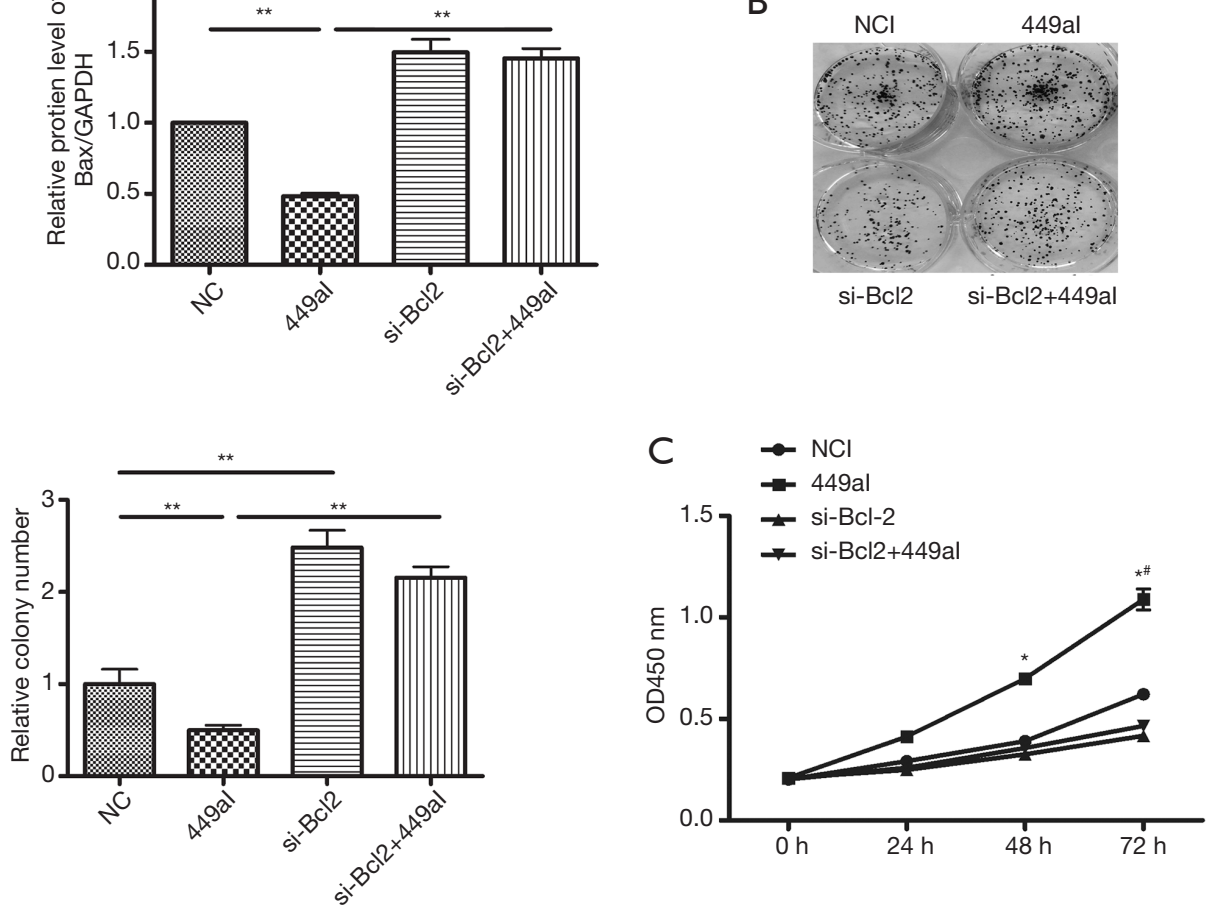

Figure 5 MiR-449a-5p regulated Eca-109 cell proliferation by targeting B-cell lymphoma 2 (Bcl-2). The protein level of Bcl-2 was silenced by transfection with Bcl-2-specific siRNA (si-Bcl-2) (A). The protein levels of Bcl-2 and Bcl-2-associated X protein (Bax) were detected by western blot (B). Silencing of Bcl-2 reversed the effect of miR-449a-5p inhibitor on the proliferation of Eca-109 cells $(\mathrm{C})$. ${ }^{*} \mathrm{P}<0.05 ;{ }^{* *} \mathrm{P}<0.01$ vs. control group; $\mathrm{n}=4$.

\section{Acknowledgments}

The authors would like to appreciate Prof. Zhelong Ge (Fourth Hospital of Hebei Medical University, Xingtai, China) for providing esophageal squamous carcinoma tissues.

Funding: This work is supported by Government Foundation Grant from Hebei Provincial Department of Education (grant no. HBGX2005-52) and the National Natural Science Foundation of China (grant no. 30371413).

\section{Footnote}

Reporting Checklist: The authors have completed the MDAR reporting checklist. Available at http://dx.doi.org/10.21037/ tcr-20-2869

Data Sharing Statement: Available at http://dx.doi. org/10.21037/tcr-20-2869

Conflicts of Interest: All authors have completed the ICMJE 
uniform disclosure form (available at http://dx.doi. org/10.21037/tcr-20-2869). The authors have no conflicts of interest to declare.

Ethical Statement: The authors are accountable for all aspects of the work in ensuring that questions related to the accuracy or integrity of any part of the work are appropriately investigated and resolved. The Ethical Review Committee of the Fourth Hospital of Hebei Medical University granted approval for this study. Each patient signed an informed consent form. The study was carried out in line with the Declaration of Helsinki (as revised in 2013).

Open Access Statement: This is an Open Access article distributed in accordance with the Creative Commons Attribution-NonCommercial-NoDerivs 4.0 International License (CC BY-NC-ND 4.0), which permits the noncommercial replication and distribution of the article with the strict proviso that no changes or edits are made and the original work is properly cited (including links to both the formal publication through the relevant DOI and the license). See: https://creativecommons.org/licenses/by-nc-nd/4.0/.

\section{References}

1. Cronin-Fenton D. A burning question: does hot green tea drinking increase the risk of esophageal squamous cell carcinoma? Clin Epidemiol 2018;10:1321-3.

2. Abnet CC, Arnold M, Wei WQ. Epidemiology of Esophageal Squamous Cell Carcinoma. Gastroenterology 2018;154:360-73.

3. Wu SG, Zhang WW, He ZY, et al. Sites of metastasis and overall survival in esophageal cancer: a population-based study. Cancer Manag Res 2017;9:781-8.

4. Liang H, Fan JH, Qiao YL. Epidemiology, etiology, and prevention of esophageal squamous cell carcinoma in China. Cancer Biol Med 2017;14:33-41.

5. Arnold M, Soerjomataram I, Ferlay J, et al. Global incidence of oesophageal cancer by histological subtype in 2012. Gut 2015;64:381-7.

6. Yu C, Tang H, Guo Y, et al. Hot Tea Consumption and Its Interactions With Alcohol and Tobacco Use on the Risk for Esophageal Cancer: A Population-Based Cohort Study. Ann Intern Med 2018;168:489-97.

7. Zhang R, Jia M, Li P, et al. Radiotherapy improves the survival of patients with metastatic esophageal squamous cell carcinoma: a propensity score matched analysis of
Surveillance, Epidemiology, and End Results database. Dis Esophagus 2019;32:doy074.

8. Lau KW, Zeng H, Liang H, et al. Bioinformatics-based identification of differentiated expressed microRNA in esophageal squamous cell carcinoma. Transl Cancer Res 2018;7:1366-75.

9. Ma Q, Song J, Chen Z, Li L, Wang B, He N. Identification of potential gene and microRNA biomarkers for colon cancer by an integrated bioinformatical approach. Transl Cancer Res 2018;7:17-29.

10. Wang Y, Yu L, Wang T. MicroRNA-374b inhibits the tumor growth and promotes apoptosis in non-small cell lung cancer tissue through the p38/ERK signaling pathway by targeting JAM-2. J Thorac Dis 2018;10:5489-98.

11. Raisch J, Darfeuille-Michaud A, Nguyen HT. Role of microRNAs in the immune system, inflammation and cancer. World J Gastroenterol 2013;19:2985-96.

12. Link A, Kupcinskas J. MicroRNAs as non-invasive diagnostic biomarkers for gastric cancer: Current insights and future perspectives. World J Gastroenterol 2018;24:3313-29.

13. Yang $X, S u W$, Chen $X$, et al. Validation of a serum 4-microRNA signature for the detection of lung cancer. Transl Lung Cancer Res 2019;8:636-48.

14. Marisi G, Cucchetti A, Ulivi P, et al. Ten years of sorafenib in hepatocellular carcinoma: Are there any predictive and/or prognostic markers? World J Gastroenterol 2018;24:4152-63.

15. Li J, Lu M, Jin J, et al. miR-449a Suppresses Tamoxifen Resistance in Human Breast Cancer Cells by Targeting ADAM22. Cell Physiol Biochem 2018;50:136-49.

16. Cheng J, Wu LM, Deng XS, et al. MicroRNA-449a suppresses hepatocellular carcinoma cell growth via G1 phase arrest and the HGF/MET c-Met pathway. Hepatobiliary Pancreat Dis Int 2018;17:336-44.

17. Gupta S, Silveira DA, Mombach JCM. Modeling the role of microRNA-449a in the regulation of the G2/M cell cycle checkpoint in prostate $\mathrm{LNCaP}$ cells under ionizing radiation. PLoS One 2018;13:e0200768.

18. Jiang T, Liu J, Mu J. Downregulation of microRNA449a5p promotes esophageal squamous cell carcinoma cell proliferation via cyclin D1 regulation. Mol Med Rep 2018;18:848-54.

19. Kale J, Osterlund EJ, Andrews DW. BCL-2 family proteins: changing partners in the dance towards death. Cell Death Differ 2018;25:65-80.

20. Adams JM, Cory S. The BCL-2 arbiters of apoptosis and their growing role as cancer targets. Cell Death Differ 
2018;25:27-36.

21. Cory S, Adams JM. The Bcl2 family: regulators of the cellular life-or-death switch. Nat Rev Cancer 2002;2:647-56.

22. Perini GF, Ribeiro GN, Pinto Neto JV, et al. BCL-2 as therapeutic target for hematological malignancies. J Hematol Oncol 2018;11:65.

23. Willis SN, Chen L, Dewson G, et al. Proapoptotic Bak is sequestered by Mcl-1 and Bcl-xL, but not Bcl2, until displaced by BH3-only proteins. Genes Dev 2005;19:1294-305.

24. Liao ZB, Tan XL, Dong KS, et al. miRNA-448 inhibits cell growth by targeting BCL-2 in hepatocellular carcinoma. Dig Liver Dis 2019;51:703-11.

Cite this article as: Jiang T, Zhao R, Du Y, Shi Z, Cheng H. MiR-449a-5p regulates the proliferation of esophageal carcinoma cell by targeting B-cell lymphoma 2. Transl Cancer Res 2020;9(11):7236-7247. doi: 10.21037/tcr-20-2869
25. Calvocoressi L, Uchio E, Ko J, et al. Prostate cancer aggressiveness and age: Impact of p53, BCL-2 and microvessel density. J Investig Med 2018;66:1142-6.

26. Li L, Zhang S, Xie D, et al. Dual inhibitor of PI3K and mTOR (NVP-BEZ235) augments the efficacy of fluorouracil on gastric cancer chemotherapy. Onco Targets Ther 2018;11:6111-8.

27. Messaritakis I, Nikolaou M, Politaki E, et al. Bcl-2 expression in circulating tumor cells (CTCs) of patients with small cell lung cancer (SCLC) receiving front-line treatment. Lung Cancer 2018;124:270-8.

(English Language Editor: J. Reynolds) 